\title{
Advances on the application of biochar in radioactive wastewater treatment
}

\author{
Bao Zizhen ${ }^{1}$, Liang Dong ${ }^{1}$, Li Honghui ${ }^{1}$, Liu Yuchen ${ }^{1}$, Cui Anxi ${ }^{1 *}$ \\ ${ }^{1}$ China Institute for Radiation Protection, Taiyuan 030000, China
}

\begin{abstract}
The domestic and foreign scholars found that biochar prepared from waste crops, animal manure, and tissues has a good adsorption effect on radioactive pollutants. Biochar is an ideal material for the adsorbent. This article summarizes the preparation methods and modification methods of biochar, and the adsorption characteristics of biochar to heavy metals and radioactive elements. This article also points out the problems and development trends in the current research of biochar.
\end{abstract}

\section{Introduction}

Agriculture is the mainstream industry in the world. Byproducts produced by agriculture, forestry, fishery, and animal husbandry from every country are tens of millions of tons each year. Most of the by-products are not used rationally and eventually incinerated, which not only wastes biological resources and emits a large amount of waste gas, but also causing the greenhouse effect, haze, and other environmental pollution problems1. Biochar is a carbon-rich material obtained by heat-treating carbonneutral carbonaceous materials (such as wood, fertilizer, or leaves) in an oxygen-free or oxygen-deficient environment. Most of the carbon-containing raw materials used in the production of biochar are regarded as waste, and the production of biochar can be regarded as " waste recycling and reuse" with a wide range of sources and low cost. Because of the low production cost and applicability of biochar, domestic and foreign scholars have begun to apply biochar in the treatment of radioactive wastewater, have conducted extensive analysis and research on the effect of its adsorption effect and preparation methods, modification methods, and conditions on the adsorption effect2. Therefore, according to researchers at home and abroad, this article summarizes and analyzes the relationship between the surface physical, chemical properties of biochar and the adsorption performance, the raw materials and preparation methods of biochar, and other factors that affect the adsorption effect of biochar, related research results. The current status of carbon research is also summarized and suggested.

\section{Surface physicochemical properties and adsorption performance of biochar}

The adsorption effect of biochar is mainly affected by the physical and chemical properties of its surface, including the specific surface area, pore size, porosity, type, and several functional groups of biochar3. Its adsorption mechanism includes electrostatic interaction, ion exchange, hydrogen bonding, surface complexation, pore filling, and $\pi-\pi$ interaction 2 .

Specific surface area, pore size, and porosity determine the number of biochar adsorption sites. The pores of biochar can divide into macropores $(>50 \mathrm{~nm}$, translation), mesopores (2 nm-50 nm, transition and adsorption), and micropores ( $<2 \mathrm{~nm}$, adsorption) based on the pore radius 3 . The surface functional groups of biochar are mainly oxygen-containing functional groups, such as carboxyl, hydroxyl, lactone, carbonyl, etc. These oxygencontaining functional groups on the surface can be combined with pollutants and are mainly ion-exchanged to realize the adsorption of pollution by biochar4.

\section{Factors affecting the adsorption effect of biochar}

The surface characteristics of biochar are determined by raw materials, pyrolysis methods, modification methods, and adsorption environment5. The carbon content and lignin content of different raw materials such as crops, animals, and plants are various, which leads to distinct adsorption effects of biochar prepared from every raw material under the same conditions. The difference in the pyrolysis process leads to the difference in the degree of biomass carbonization and the pore structure of the biochar, which affects the adsorption effect of the biochar. Biochar modification divides into physical modification and chemical modification, modification can change the pore structure of the biochar surface, the type, and quantity of energy groups, etc., increase the maximum adsorption capacity of biochar, and improve the adsorption efficiency. The modification principle of the sexual method is different, and the adsorption effect is also different. The environmental conditions of the adsorption process, such as $\mathrm{pH}$, temperature, etc., will affect the adsorption effect

*Corresponding author's e-mail: cuianxi@cirp.org.cn 
of biochar. In most cases, the adsorption efficiency of the adsorption process under acidic and warmer temperature conditions is higher than that under alkaline, high temperature, or low-temperature conditions. Desorption will occur under high-temperature conditions.

\subsection{The influence of raw materials on the adsorption effect of biochar}

The raw materials for preparing biochar include agricultural and forestry wastes (such as straw, rice husk, leaves, wood residue, etc.), animal manure, sludge, etc. Biomass is mainly composed of lignin, cellulose, and hemicellulose. Among them, the most necessary factor affecting the yield of biochar is the content of lignin in the biomass. The higher the lignin content, the higher the yield of biochar, and the pore structure is also more complex6.

Table 1 Adsorption of different biochars to several heavy metal ions.

\begin{tabular}{cccc}
\hline Raw material & Adsorption object & $\begin{array}{c}\text { Maximum adsorption } \\
\text { capacity } / \mathrm{mg} \cdot \mathrm{g}-1\end{array}$ & References \\
\hline Sunflower straw & $\mathrm{Sr}^{2+}$ & 20.84 & 7 \\
Rice straw & $\mathrm{Cd}^{2+}$ & 12.17 & 9 \\
Rice husk & $\mathrm{Cr}^{6+}$ & 23.09 & 10 \\
Enteromorpha & $\mathrm{Cr}^{6+}$ & 23.00 & 11 \\
Rape stalk & $\mathrm{Cd}^{2+}$ & 32.74 & 12 \\
Corn stalk & $\mathrm{Cr}^{6+}$ & 21.7 & 13 \\
Peanut shell & $\mathrm{Ni}^{2+}$ & 20.67 & 14 \\
Bagasse & $\mathrm{Hg}^{2+}$ & 76 & 15 \\
Corn cob & $\mathrm{Cd}^{2+}$ & 28.16 & 16 \\
Bamboo shavings & $\mathrm{Cr}^{6+}$ & 18.45 & 17 \\
\hline
\end{tabular}

Commonly raw materials researchers used to prepare biochar mainly include: corn cobs, corn stalks, rice straw, peanut shells, wheat stalks, bagasse, and pine wood. Bashir et al. studied the adsorption effect of straw biochar on $\mathrm{Cd}^{2+}$ and obtained a maximum adsorption capacity of $12.17 \mathrm{mg} / \mathrm{g} 9$. Ma et al. studied the adsorption effect of rice husk biochar on $\mathrm{Cr}^{6+}$, and the maximum adsorption capacity obtained was $23.09 \mathrm{mg} / \mathrm{g} 10$. Chen et al. studied the adsorption effect of Enteromorpha biochar on $\mathrm{Cr}^{6+}$, and the maximum adsorption capacity obtained was 23.00 $\mathrm{mg} / \mathrm{g} 11$. Li et al. studied the adsorption effect of rape stalk biochar on $\mathrm{Cd}^{2+}$, and the maximum adsorption capacity obtained was $32.74 \mathrm{mg} / \mathrm{g} 12$. An et al. studied the adsorption effects of biochar with corn stalks and peanut shells as raw materials on $\mathrm{Cr}^{6+}$ and $\mathrm{Ni}^{2+}$, and the maximum adsorption capacities obtained were $21.7 \mathrm{mg} / \mathrm{g}$ and 20.67 $\mathrm{mg} / \mathrm{g}$, respectively13-14. Li et al. studied the adsorption effect of bagasse biochar on $\mathrm{Hg}^{2+}$, and the maximum adsorption capacity obtained was $76 \mathrm{mg} / \mathrm{g} 15$. Luo et al. studied the adsorption effect of corncob biochar on $\mathrm{Cd}^{2+}$, and the maximum adsorption capacity obtained was 28.16 $\mathrm{mg} / \mathrm{g} \mathrm{16}$. Huang et al. studied the adsorption effect of bamboo shavings biochar on $\mathrm{Cr}^{6+}$, and the maximum adsorption capacity obtained was $18.45 \mathrm{mg} / \mathrm{g} 17$.

Biochar prepared from biomass as a raw material has been studied emphatically as a low-cost and highefficiency adsorbent in recent years, and has begun to be used to treat radioactive wastewater. However, the maximum adsorption capacity of the original biochar is relatively low to meet the actual wastewater treatment requirements, the practical application of biochar in wastewater is limited, and it needs to be modified to increase the adsorption capacity.

\subsection{The influence of preparation method on the adsorption effect of biochar}

The methods for producing biochar from carbonaceous materials (mainly biomass) are pyrolysis and hydrothermal carbonization. The yield of biochar produced by these processes varies with operating conditions, biomass type, and reaction medium. The most common method is pyrolysis. According to the difference of pyrolysis temperature, heating rate, and residence time, it can divide into slow pyrolysis and fast pyrolysis, as well as hydrothermal carbonization, gasification, and flash carbonization that are less used. The main characteristics of the pyrolysis method shown in Table 1. At present, slow pyrolysis is the most widely used pyrolysis method. The pyrolysis temperature is between $250{ }^{\circ} \mathrm{C}-700{ }^{\circ} \mathrm{C}$, and the retention time is several hours, the main instrument used is tube type furnace and muffle furnace, this method has mature technology, simple operation, and high yield; the rapid pyrolysis temperature is about $500{ }^{\circ} \mathrm{C}$, the heating rate is about $20{ }^{\circ} \mathrm{C}-50{ }^{\circ} \mathrm{C} / \mathrm{min}$, and the retention time is a few seconds, the main instruments used are fixed bed and fluidized bed reactor, this preparation method mainly produces tar, and the yield of biochar is low; the hydrothermal carbonization pyrolysis temperature is $200{ }^{\circ} \mathrm{C}$ - $250{ }^{\circ} \mathrm{C}$ directly, and keep for several hours, the instrument is a hydrothermal reactor. Because the pyrolysis temperature of hydrothermal carbonization is relatively low, the reaction is mild, and the stabilization of biochar is also not good; The above preparation methods inquire biomass to carry out in an oxygen-limited environment, if the oxygen is too high, it may cause further ashing of biochar. Besides, the pyrolysis 
temperature and holding time are not too high or too long, which may cause the internal structure of biochar to collapse.

Table 2 Conditions and characteristics of biochar preparation methods.

\begin{tabular}{|c|c|c|c|c|c|}
\hline $\begin{array}{l}\text { Pyrolysis } \\
\text { method }\end{array}$ & $\begin{array}{l}\text { Pyrolysis } \\
\text { temperature }\end{array}$ & Heating rate & Holding time & Main instrument & Features \\
\hline $\begin{array}{c}\text { slow } \\
\text { pyrolysis }\end{array}$ & $250{ }^{\circ} \mathrm{C}-700{ }^{\circ} \mathrm{C}$ & $5-10{ }^{\circ} \mathrm{C} / \mathrm{min}$ & several hours & $\begin{array}{l}\text { Tube furnace } \\
\text { and muffle } \\
\text { furnace }\end{array}$ & $\begin{array}{l}\text { high biochar yield } \\
\text { rate, simple } \\
\text { operation }\end{array}$ \\
\hline fast pyrolysis & $\sim 500{ }^{\circ} \mathrm{C}$ & $\begin{array}{c}20{ }^{\circ} \mathrm{C}-50{ }^{\circ} \mathrm{C} \\
\qquad / \mathrm{min}\end{array}$ & $\sim 1 \mathrm{~s}$ & $\begin{array}{l}\text { fixed bed and } \\
\text { fluidized bed } \\
\text { reactors }\end{array}$ & $\begin{array}{c}\text { low biochar yield } \\
\text { rate }\end{array}$ \\
\hline $\begin{array}{l}\text { hydrothermal } \\
\text { carbonization }\end{array}$ & $200{ }^{\circ} \mathrm{C}-250{ }^{\circ} \mathrm{C}$ & $\sim 10{ }^{\circ} \mathrm{C} / \mathrm{min}$ & several hours & $\begin{array}{l}\text { Hydrothermal } \\
\text { reaction kettle }\end{array}$ & $\begin{array}{l}\text { reaction conditions } \\
\text { are warm, biochar } \\
\text { has low stability }\end{array}$ \\
\hline
\end{tabular}

Wang chose five kinds of biomass with good adsorption capacity and selected three pyrolysis processes of slow pyrolysis, fast pyrolysis, and flash gasification to prepare biochar to adsorb heavy metal ions and methylene blue. The specific surface area of biochar obtained by slow pyrolysis at low temperature is smaller, but the types of oxygen-containing functional groups are more abundant, and the adsorption efficiency is higher; the biochar prepared by rapid pyrolysis has a large specific surface area, low PH value, high oxygen-to-carbon ratio, and high adsorption efficiency; gasification process is mainly composed of a precipitation reaction, ion exchange, and $\pi$ $\pi$ interaction, with high adsorption efficiency. The efficiency of gasification and fast pyrolysis is slightly higher than that of slow pyrolysis18. Fan chooses hydrothermal carbonization and pyrolysis methods to prepare biochar from corn stalks. The most significant influence on hydrothermal carbonization is temperature. The volatile content is higher than that of pyrolysis biochar. It has good combustion performance and high oxygen content, which make hydrothermal carbonization more suitable for preparing fuel biochar21.

\subsection{The effect of modification methods on the adsorption effect of biochar}

Biochar has great prospects in wastewater treatment, and relevant scholars at home and abroad have done a lot of research on wastewater treatment. At present, the number of effective functional groups such as carboxyl and hydroxyl groups on the surface of biochar can increase through chemical modification and physical modification, and physical properties such as the porosity, specific surface area, and pore size of biochar will increase.

\subsection{1. chemical modification. Chemical modification} mainly improves the adsorption effect of biochar by increasing the type and number of functional groups on the surface of biochar and increasing the oxygen content. Current modification methods include modification with chemical reagents, preparation of biochar-based composite materials, etc., which can increase the number of hydroxyl and carboxyl groups on the surface of biochar. Modification with ammonia water can also generate new nitrogen-containing functional groups on the surface of biochar, such as amino groups. Chemical modification can sharply increase the adsorption sites of biochar and increase the chance of surface functional groups reacting with radioactive contaminants. Through chemical reagent activation and modification methods, such as $\mathrm{HNO}_{3}, \mathrm{KOH}$, $\mathrm{KMnO}_{4}$, etc., Han et al. modified animal feces biochar with $\mathrm{H}_{2} \mathrm{O}_{2}$ and $\mathrm{NaOH}$, respectively. The adsorption capacity of biochar modified by $\mathrm{NaOH}$ for uranium increased from $50.2 \mathrm{mg} / \mathrm{g}$ to $221.4 \mathrm{mg} / \mathrm{g} \mathrm{22}$; Chen et al. modified the original chicken feather biochar with phosphoric acid, and the modified biochar had a $\mathrm{Pb}$ adsorption capacity from $18.423 \mathrm{mg} / \mathrm{g}$ to $55.425 \mathrm{mg} / \mathrm{g} 23$; Attia et al. modified pomegranate peel biochar with sodium lauryl sulfate, the adsorption capacity for cesium increased from $70.44 \mathrm{mg} / \mathrm{g}$ to $133.09 \mathrm{mg} / \mathrm{g}$, and the adsorption capacity for europium increased from 96.72 $\mathrm{mg} / \mathrm{g}$ to $202.01 \mathrm{mg} / \mathrm{g} 24$; Wang et al. modified the bamboo biochar with polyethyleneimine, and the modified acidic biochar's adsorption capacity for uranium increased from $20.1 \mathrm{mg} / \mathrm{g}$ to $212.7 \mathrm{mg} / \mathrm{g}$, alkaline biochar reached 185.6 $\mathrm{mg} / \mathrm{g} 25$; Yang et al. used amino-modified sawdust biochar, and the modified biochar's adsorption capacity for copper reached $17.01 \mathrm{mg} / \mathrm{g}$ from $12.49 \mathrm{mg} / \mathrm{g} 26$; Li et al. modified banyan aerial root biochar with potassium permanganate, and the modified uranium adsorption capacity increased from $19.08 \mathrm{mg} / \mathrm{g}$ to $27.29 \mathrm{mg} / \mathrm{g} 27$. By preparing biochar composite materials, such as chitosan-biochar composite materials, kaolin-biochar composite materials, $\mathrm{Fe}_{3} \mathrm{O}_{4-}$ biochar composite materials, etc. Li et al. used siderite and straw to prepare magnetic biochar composites. After modification, the adsorption capacity of uranium reached $52.63 \mathrm{mg} / \mathrm{g}$ from $2.12 \mathrm{mg} / \mathrm{g} 28$; Gan et al. used zinc nitrate solution and bagasse to prepare zinc biochar composite materials, and the modified adsorption capacity of chromium has reached $102.66 \mathrm{mg} / \mathrm{g}$ from $82 \mathrm{mg} / \mathrm{g} 29$; Khan et al. used ferric nitrate solution and corn stalks to prepare magnetic biochar, and the modified biochar's adsorption capacity for cadmium reached $46.9 \mathrm{mg} / \mathrm{g}$ from $14.32 \mathrm{mg} / \mathrm{g} 30$. There is also the reagent-free modification of biochar by UV ultraviolet irradiation. Peng et al. used ultraviolet lamp irradiation to treat cornstalk biochar. The adsorption capacity of the treated biochar for chromium increased from $1.11 \mathrm{mg} / \mathrm{g}$ to $20.04 \mathrm{mg} / \mathrm{g} 31$. 
3.3.2. Physical modification. The physical modification can cause the biochar to produce a porous structure, increase the porosity and specific surface area of the biochar, and increase the maximum adsorption capacity by passing water vapor, air, flue gas, etc. at high-temperature thermal damage to the biochar. For example, Dai et al. treated crop biochar such as straw, sludge, corn stalks, corn cobs, and other crops with hot air. The modified corn cobs and sludge showed superior adsorption effects, and the adsorption capacity for uranium increased from 68.82 $\mathrm{mg} / \mathrm{g}$ and $78.66 \mathrm{mg} / \mathrm{g}$ to $163 \mathrm{mg} / \mathrm{g}$ and $97 \mathrm{mg} / \mathrm{g} 32$. Lu used acid bamboo shoot husks to prepare biochar and modified it by roasting. The adsorption capacity of chromium increased from $63.11 \mathrm{mg} / \mathrm{g}$ to $102.77 \mathrm{mg} / \mathrm{g} 32$. Fahmi et al. used oil palm empty fruit bunches as raw materials to prepare biochar, and grind them into biochar of different particle sizes, namely coarse charcoal $(>2000 \mu \mathrm{m})$, medium charcoal $(250 \mu \mathrm{m}-500 \mu \mathrm{m})$, fine charcoal $(<50$ $\mu \mathrm{m})$ The maximum adsorption capacity for $\mathrm{Pb}$ is 54.95 $\mathrm{mg} / \mathrm{g}, 58.14 \mathrm{mg} / \mathrm{g}, 103.09 \mathrm{mg} / \mathrm{g}$, and it concluded that the smaller the particle size of the milled biochar, the larger the maximum adsorption capacity and the better the adsorption effect33.

The adsorption effect of modified biochar by different methods has sharply improved, the maximum adsorption capacity has also increased more than ten times or even dozens of times. The adsorption rate has increased, and the adsorption effect has significantly improved. The research of modified biochar and its application in wastewater treatment has also become a central issue in recent years.

According to the research status of modified biochar, the current modification methods of biochar mainly include chemical reagents, especially strong acids, strong bases, and strong oxidants, which will lead to a large amount of wastewater and other by-products after the modification of biochar, and these products need additional treatment, and then limit the practical application of modified biochar. Therefore, reagent-free modification and natural materials are used to treat biochar, which not only ensures the adsorption efficiency of modified biochar but also reduces the by-products in the modification process.

\subsection{The influence of environmental conditions on the adsorption effect of biochar}

Scholars at home and abroad have conducted single-factor experiments on biochar, mainly considering the influence of $\mathrm{pH}$, temperature, contact time, the amount of adsorbent, and competing cations on the adsorption effect of biochar, to study the adsorption conditions suitable for biochar. At present, most biochar has a good adsorption effect under acidic conditions. After some time of contact, the adsorption will reach equilibrium. The adsorption process will be better at warmer temperatures. If the temperature is too high, the adsorption equilibrium or even desorption will be reached in advance. When the wastewater contains competing cations, the cations replace the target ions and combine with the biochar, which will affect the adsorption effect of the biochar on the target ions. An et al. conducted single-factor experiments on $\mathrm{PH}$, contact time, and temperature, and found that the adsorption effect of $\mathrm{PH}$ was the best at 2 and 7 , room temperature, and the adsorption efficiency decreased with the increase of temperature when the temperature exceeded $25{ }^{\circ} \mathrm{C}$, the adsorption equilibrium reached in about 8-10 hours 13 . Attia et al. studied the influence of $\mathrm{pH}$, temperature, and contact time on the adsorption effect, and found that under neutral or weak acid conditions, the adsorption can reach equilibrium within one hour at $60^{\circ} \mathrm{C} 24 . \mathrm{Li}$ et al. studied the effects of $\mathrm{pH}$ and contact time on the adsorption effect of biochar. The original biochar has the best adsorption effect when the $\mathrm{pH}$ is 5 , and the biochar modified with potassium permanganate has a $\mathrm{pH}$ value of 3 . The adsorption effect is the best, and the adsorption efficiency does not change with the increase of the $\mathrm{pH}$ value, and the adsorption time quickly reaches the adsorption equilibrium within 10 minutes 27 . Dai et al. studied the effects of $\mathrm{pH}$, ionic strength, and competitive cations on the adsorption of biochar, and found that when the $\mathrm{pH}$ value is $5-6$, it takes $5-10$ hours to reach the adsorption equilibrium. At the same time, the $\mathrm{Ca}^{2+}$ is more competitive and has a terrible impact. The adsorption effect of biochar on uranium, while the adsorption effect of $\mathrm{Na}^{+}$on biochar is less32. The differences in the research results of related influencing factors by different scholars are mainly due to the differences in the types of biochar raw materials, modification methods, and the initial concentration of the simulated waste liquid and the amount of adsorbent added.

\section{Research progress of biochar in radioactive wastewater treatment}

At present, research on the application of biochar in radioactive wastewater has been increasing year by year, especially the improvement of the adsorption effect of biochar modification methods. Ai et al. used sunflower straw to adsorb $\mathrm{Sr}^{2+}$, and the maximum adsorption capacity was only $20.84 \mathrm{mg} / \mathrm{g} 6-7$. Irene et al. used different temperatures to study the effect of pyrolysis of green pepper biomass on the adsorption performance of $\mathrm{Co}^{2+}$. The study found that the adsorption performance was the best at $450{ }^{\circ} \mathrm{C}$, and the maximum adsorption

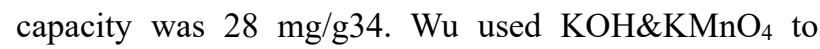
modify coconut shell biochar to study its adsorption effect on uranium in wastewater. After modification, the removal rate of $\mathrm{U}^{6+}$ reached $96.6 \% 35$. Jang et al. wrapped the straw biochar with sodium alginate to modify the biochar. They studied the adsorption effect of the modified biochar on $\mathrm{Sr}^{2+}$ and found that its maximum adsorption capacity for $\mathrm{Sr}^{2+}$ reached $175.95 \mathrm{mg} / \mathrm{g}$, the removal rate reached 98\%37. Different modification methods have significant differences in the adsorption effect and maximum capacity of various ions. There are many radioactive ions in actual radioactive wastewater. Finding a suitable modification plan to achieve efficient adsorption of multiple target ions is still the focus of future research. 


\section{Conclusions}

The raw materials of biochar come from various animal and agricultural and forestry wastes, which not only solves the problem of waste disposal but also improves the utilization rate of waste resources. The preparation process is environmentally friendly and safe. At the same time, it was also found that biochar has an excellent adsorption effect on metal ions in the process of radioactive wastewater treatment. At present, the application prospect of biochar in the treatment of radioactive wastewater is excellent. The research on biochar at home and abroad is mainly in the aspect of modification, discussing the adsorption characteristics and mechanism of biochar, and how to use different modification methods to increase the maximum adsorption capacity of biochar. Although great progress has been made, the research on some key issues is still insufficient. In the future, we can focus on the following aspects:

(1) Although the adsorption effect of biochar is good, the maximum adsorption capacity is large, but it cannot control the types of adsorbed ions at the physically adsorbed aspect. Therefore, it is necessary to do some research on chemical adsorption modification, strengthen the selectivity of biochar in radioactive wastewater for target ions such as uranium, strontium, cesium, and cobalt ions, and reduce the effect of other impurity ions such as sodium, chromium, cadmium, and copper ions on the adsorption effect of biochar.

(2) With the application of biochar in the treatment of radioactive wastewater becomes more and more extensive, the use of amount chemical modification reagents will lead to more by-products, increase the pressure on wastewater treatment and bring new problems to the environment. Choose a safer and more environmentally friendly way to modify biochar to avoid or reduce the production of by-products.

(3) The use of biochar to treat radioactive wastewater is a process of converting large-volume, liquid radioactive waste into small-volume, solid radioactive waste. Further research should be done on the post-treatment of highactivity solid pollutants and modified by-products produced by biochar adsorbing radioactive wastewater.

(4) The time of preparation and modification of biochar is relatively long, and the single output is relatively small, which limits the wide application of biochar in radioactive wastewater treatment. Next step, we will further study how to reduce the cost and time of modification, establish a complete radioactive wastewater treatment system including biochar, and increase column test research to provide a theoretical basis on large-scale applications of biochar in various fields such as energy and military.

\section{Acknowledgement}

This research was supported by Foundation of The National Key Research and Developmeng program of China (2018YFC0810301).

\section{References}

1. Jia, Q.H., Shi Y.B., Xu, X.J., Sun, L. Research progress on application of modified corncob in waste water treatment[J]. New Chemical Materials, 2020, 48(07):34-37.

2. Premarathna, K.S.D., Rajapaksha, A.U., Sarkar, B. et al. Biochar-based engineered composites for sorptive decontamination of water: A review. 2019, 372:536550 .

3. Xie, Q., Zhang, X.L., Li L.T., Jin, L. Porosity adjustment of activated carbon: theory approaches and practice[J]. New Carbon Materials,2005(02):183190.

4. Fan, Y. Z., Wang, B.Z. Surface chemistry of activated carbon[J]. Coal Coversion,2000(04):26-30.

5. Chen, K.X., He, M.J., Zhang, J., Peng, S.M. Research progress on the mechanism of biochar for removal of typical water pollutants[J]. Functional Materials, 2020, 51(12):12058-12064.

6. Deng, X.D. Biomass carbon Materials for effective simulative nuclide stronium removal[D]. Southwest University of Science and Technology. 2016. https://kns.cnki.net/kcms/detail/detail.aspx?FileNam $\mathrm{e}=1016113302$. nh\&DbName $=$ CMFD2017

7. Ai, L. The adsorption characteristics for sranium and stronium on sunflower biomass[D]. Southwest University of Science and Technology. 2014. https://kns.cnki.net/kcms/detail/detail.aspx?FileNam $\mathrm{e}=1014422787 . n$ h $\&$ DbName $=$ CMFD2015

8. Zhang, R. The application of biochar in the sorption radionuclides[D]. University of Science and Technology of China. 2017. https://kns.cnki.net/kcms/detail/detail.aspx?FileNam $\mathrm{e}=1017071192$. nh\&DbName $=$ CDFD2017

9. Bashir, S., Jun, Z., Fu, Q.L., Hu, H.Q. Comparing the adsorption mechanism of $\mathrm{Cd}$ by rice straw pristine and $\mathrm{KOH}$-modified biochar[J]. Environmental Science and Pollution Research,2018,25(12).

10. Ma, Y., Liu, W.J., Zhang N., Li, Y.S., Jiang, H., Sheng, G.P. Polyethylenimine modified biochar adsorbent for hexavalent chromium removal from the aqueous solution[J]. Bioresource Technology,2014,169.

11. Chen, Y.Y., Wang B.Y., Xin, J., Sun, P., Wu, D. Adsorption behavior and mechanism of $\mathrm{Cr}(\mathrm{VI})$ by modified biochar derived from Enteromorpha prolifera[J]. Ecotoxicology and Environmental Safety,2018,164.

12. Li, B., Yang, L., Wang, C.Q., Zhang, Q.P., Liu, Q.C., Li, Y.D., Xiao, R. Adsorption of Cd(II) from aqueous solutions by rape straw biochar derived from different modification processes[J]. Chemosphere,2017,175.

13. An, Q., Li, X.Q., Nan, H.Y., Yu, Y., Jiang, J.N. The potential adsorption mechanism of the biochars with different modification processes to $\mathrm{Cr}(\mathrm{VI}) \cdot[\mathrm{J}]$. Environmental science and pollution research international,2018.

14. An, Q., Jiang, Y.Q., Nan, H.Y., Yu, Y., Jiang J.N. 
Unraveling sorption of nickel from aqueous solution by $\mathrm{KMnO} 4$ and $\mathrm{KOH}$-modified peanut shell biochar: Implicit mechanism[J]. Chemosphere,2019,214.

15. Li, B.Y., Li, K.Q. Effect of nitric acid pre-oxidation concentration on pore structure and nitrogen/oxygen active decoration sites of ethylenediamine -modified biochar for mercury(II) adsorption and the possible mechanism $[\mathrm{J}]$. Chemosphere, 2018.

16. Luo, M.K., Lin, H., Li, B., Dong, Y.B., He, Y.H., Wang L. A novel modification of lignin on corncobbased biochar to enhance removal of cadmium from water[J]. Bioresource Technology,2018,259.

17. Huang, D.L., Liu, C.H., Zhang, C., Deng, R, Wang, R.Z., Xue, W.J., Luo H., Zeng, G.M., Zhang, Q., Guo, X.Y. Cr(VI) removal from aqueous solution using biochar modified with $\mathrm{Mg}$ /Al-layered double hydroxide intercalated with ethylenediaminetetraacetic acid[J]. Bioresource Technology, 2019,276.

18. Yan, W. Study on characteristics different biochar and mechanisms for removing heavy metal ions in solution[D]. Shanghai Jiao Tong University,2018. https://kns.cnki.net/kcms/detail/detail.aspx?FileNam $\mathrm{e}=1019641211$.nh $\&$ DbName $=$ CDFD2020

19. Gao, X.L., Guo, C., Zhang, H.F., etc. Research progress in the adsorption of strontium ions [J]. China Mining Magazine.2011, 20(12): 103-107.

20. Du, C., Zuo, R. Adsorption of cesium-containing wastewater by typical materials [D]. Journal of Beijing Normal University (Natural Science) [J]. 2020, 56(2): 188-194.

21. Fan, F.Y. Study on preparation of biochar based on hydrothermal carbonization and pyrolysis of corn straw[D]. Hefei University of Technology, 2017. https://kns.cnki.net/kcms/detail/detail.aspx?FileNam $\mathrm{e}=1018271764$.nh\&DbName $=$ CDFD2019

22. Han, L.F. Highly effificient U(VI) removal by chemically modifified hydrochar and pyrochar derived from animal manure[J]. Journal of Cleaner Production. 2020, 264.

23. Chen, H.Y., Li, W.Y., Wang, J.J., Xu, H.J., Liu, Y.L., Zhang, Z, Li, Y.T., Zhang, Y.L. Adsorption of cadmium and lead ions by phosphoric acid-modifified biochar generated from chicken feather: Selective adsorption and inflfluence of dissolved organic matter[J]. Bioresource Technology. 2019,292.

24. Attia, L.A, Youssef, M.A, Abdel, M. Feasibility of radioactive cesium and europium sorption using valorized punica granatum peel: kinetic and equilibrium aspect[J]s.Separation Science and Technology,2021,56(2).

25. Wang, X., Feng J.H., Cai, Y.W., Fang, M., Kong M.G., Alsaedi, A., Hayat, T., Tan, X.L. Porous biochar modified with polyethyleneimine (PEI) for effective enrichment of $\mathrm{U}(\mathrm{VI})$ in aqueous solution[J]. Science of the Total Environment,2020,708.

26. Yang, G.X., Jiang, H.. Amino modification of biochar for enhanced adsorption of copper ions from synthetic
wastewater[J]. Water Research,2014,48.

27. Li, N., Yin, M.L., Daniel, Tsang, C.W., Yang, S.T., Liu J., Li, X., Song, G., Wang, J. Mechanisms of U(VI) removal by biochar derived from Ficus microcarpa aerial root: A comparison between raw and modified biochar[J]. Science of the Total Environment, 2019,697.

28. Li, M.X., Liu, H.B., Chen, T.H., Dong, C., Sun, Y.B. Synthesis of magnetic biochar composites for enhanced uranium(VI) adsorption[J]. Science of the Total Environment,2018

29. Gan, C., Liu, Y.G., Tan, X.F., Wang, S.F., Zeng, G.M., Zheng, B.H., Li, T.T., Jiang, Z.J., Liu, W. Effect of porous Zinc-biochar nanocomposites on $\mathrm{Cr}(\mathrm{VI})$ adsorption from aqueous solution[J]. RSC Advances.2015,5.

30. Khan, Z.H., Gao, M.L., Qiu, W.W., Islam, M.S., Song, Z.G. Mechanisms for cadmium adsorption by magnetic biochar composites in an aqueous solution[J]. Chemosphere,2020,246.

31. Peng, Z.Y., Zhao, H., Liu, H.H., Wang, L., Huang, H., Nan, Q., Tang, J.C. UV modification of biochar for enhanced hexavalent chromium removal from aqueous solution[J]. Springer Berlin Heidelberg, 2018,25(11).

32. Dai, L.C., Li, L., Zhu, W.K., Ma, H.Q., Huang, H.G., Lu, Q., Yang, M., Ran, Y. Post-engineering of biochar via thermal air treatment for highly efficient pro motion of uranium(VI) adsorption[J]. Bioresource Technology. 2020,298.

33. Lu, H.J. Preparation of bamboo shoot shell biochar by torrefaction and its adsorption Properties of $\mathrm{Cr}(\mathrm{VI})$ from aqueous solution[D].Fuzhou University, 2018. https://kns.cnki.net/kcms/detail/detail.aspx?F ileName $=1019101238$.nh $\&$ DbName $=$ CMFD2020

34. Fahmi, A.H., Samsuri A.W., Jola H., Singh D. Physical modification of biochar to expose the inner pores and their functional groups to enhance lead adsorption[J]. RSC Advances. 2018, 8, 38270.

35. Irene, I.R., Mónica, C., Gabriel B., María Ángeles, M.L. Greenhouse Crop Residue and Its Derived Biochar: Potential as Adsorbent of Cobalt from Aqueous Solutions[J]. Water,2020,12(5).

36. $\mathrm{Wu}, \mathrm{S}$.Q. Adsorption of uranium(VI) by modified coconut biochar[D]. University of South China,2019. https://kns.cnki.net/kcms/detail/detail.aspx?FileNam $\mathrm{e}=1019232865 . \mathrm{nh} \& \mathrm{DbName}=\mathrm{CMFD} 2020$

37. Jang, J., Miran, W., Sewu, D., Divine, Nawaz, M., Shahzad, A., Woo, S.H., Lee, D.S. Rice straw-based biochar beads for the removal of radioactive strontium from aqueous solution[J]. Science of the Total Environment,2018,615. 